\title{
OPORTUNIDADES PROBATORIAS NO REGLAMENTADAS EXPLÍCITAMENTE EN LOS NUEVOS PROCEDIMIENTOS LABORALES
}

\author{
EVIDENTIARY OPPORTUNITIES NOT EXPLICITLY REGULATED IN THE NEW LABOR \\ LAW PROCEDURES
}

\section{Felipe Utman Suárez*}

\section{INTRODUCCIÓN}

El nuevo sistema de jurisdicción laboral chileno $^{1}$ se plantea como una alternativa más rápida y eficaz para administrar justicia, sobre todo para los principales destinatarios de esta rama de la judicatura: los trabajadores.

Sin embargo, el nuevo régimen no parece estar exento de inconvenientes. Sus virtudes pueden también ser manifestación de algunas debilidades. A modo de ejemplo, su celeridad se relaciona con menos instancias para probar la verdad de todos los hechos directos y circunstanciales, situación que tal vez quiso ser enmendada otorgándosele al juez más facultades inquisidoras para suplir las eventuales deficiencias de los abogados en la incorporación de evidencias, pero esta autoridad podría afectar la estrategia de los apoderados e incluso sobrepasar su labor llegando a denegarles el aporte de pruebas relevantes ${ }^{2}$, develando con ello la disputa de dos valores subyacentes: celeridad y ver$d a d^{3}$. Al efecto, es lógico pretender que las sen-

* Egresado de Derecho, Pontificia Universidad Católica de Chile. Correo electrónico: fautman@uc.cl ${ }^{1}$ La Ley $\mathrm{N}^{\circ} 20.087$ modificó el Libro V del C. del Trabajo incorporando los nuevos procedimientos.

${ }^{2}$ Sobre este concepto, véase TARUFfo (2008) pp. 38 a 41 ( $\$ 20$ a 22).

3 Dichos principios, verdad y celeridad, están consagrados en algunas normas del nuevo procedimiento laboral. La celeridad se puede encontrar en los artículos 425 inciso $1^{\circ}, 428,450$ y 500 inciso $5^{\circ}$ del C. del Trabajo, los que buscan disminuir la dilatación de las actuaciones procesales, a su vez que tampoco dan pie para crear o dividir mayormente las etapas que fijan. Por otra parte, la búsqueda de la verdad, entendida como un fin del proceso, se puede hallar en el artículo 429 inciso $1^{\circ}$, tencias se acerquen lo más posible a la verdad de los hechos en conflicto ${ }^{4}$, conocimiento que generalmente se logra mediante el contacto con las pruebas. Empero, no siempre se logra contar con dichos medios en las ocasiones que establece la ley y más se dificulta si dichos eventos son escasos. Por otro lado, más oportunidades probatorias -aparejadas de eventuales incidentes-, podrían desgastar a los intervinientes y abultar los antecedentes del proceso, entorpeciendo la labor del juez quien deberá destinar más recursos y tiempo para la resolución del caso ${ }^{5}$, demora que daña la paz social y desencanta a los ciudadanos, quienes otrora, han debido observar en el ambiente jurisdiccional juicios interminables.

En esa línea, los nuevos procedimientos -procesal penal, de familia y ahora último el laboral- han tendido a acelerar la manera de resolver los conflictos, rapidez que llevada al extremo podría afectar el conocimiento efectivo de la verdad al disminuir las instancias probatorias y, por ende, en la justicia que se quiere impartir ${ }^{6}$. Aun en ese contexto, este trabajo

norma que faculta al juez para ir más lejos de lo que las partes le han intentado mostrar. Mismo principio se aprecia en los artículos $453 \mathrm{~N}^{\circ} 9$ y $454 \mathrm{~N}^{\text {os }} 4$ inciso $2^{\circ}, 6$ inciso $1^{\circ}$, y 9 inciso $2^{\circ}$ de igual cuerpo legal.

4 TARuffo (2008) pp. 22 y $23(\$ 7)$.

5 Taruffo $(2008)$ pp. $37(\$ 19), 39(\$ 21)$ y $50(\$$ 31).

${ }^{6}$ No es materia de este ensayo discurrir si efectivamente el nuevo procedimiento laboral consagra la búsqueda de la verdad como un fin en sí mismo, ya que pueden hallarse normas no acordes con este propósito, v. gr, las que recogen el principio de celeridad y el artículo $453 \mathrm{~N}^{\circ} 1$ inciso $6^{\circ}$ en relación a su $\mathrm{N}^{\circ} 3$ inciso $2^{\circ}$ del C. del Trabajo, que autorizan 
pretende proponer cómo lograr que las partes tengan más oportunidades para mostrar la verdad en los nuevos procedimientos laborales, buscando alternativas que no están detalladamente reguladas en el código, pero sí en sus directrices generales y en la armonía de sus normas con las del resto de los procedimientos de audiencia.

\section{OPORTUNIDADES PARA PRESENTAR EVIDENCIAS}

\subsection{Oportunidades Reguladas explícita-} mente por el C. Del Trabajo

Dentro de sus diversos procedimientos se logra diferenciar al menos cinco momentos para rendir pruebas, sea de manera general o específica, dependiendo de los medios o materias a probar:

a. Con la solicitud de una medida precautoria antes o durante la tramitación del juicio:

El artículo 444 inciso $4^{\circ}$ exige acreditar razonablemente el fundamento de una medida cautelar que se solicita, lo que sugiere el aporte de pruebas específicas para ello.

b. Con la interposición de la demanda:

- En el Procedimiento de Aplicación General (PAG): Deben acompañarse aquellos documentos que den cuenta de actuaciones administrativas, o la resolución emitida por una entidad previsional o de seguridad social o la resolución final de una entidad fiscalizadora, contra la que se reclame ${ }^{7}$;

al juez a dictar sentencia sobre la base del silencio del demandado, dando por tácitamente probados hechos sobre los cuales probablemente no existen mayores evidencias que acrediten lo expuesto por el actor. Sin embargo, atendidas las mayores facultades inquisitivas del juez, este debiera tener mayor interés en acceder a la verdad de los hechos puesto que al menos goza de más herramientas que en el antiguo procedimiento y que otros jueces. Véase también TARuffo (2008) p. 51 (\$32).

${ }^{7}$ Artículo 446 incisos $2^{\circ}$ y $3^{\circ}$ del C. del Trabajo.
- En el Procedimiento de Tutela Laboral (PTL): Deben acompañarse el acta de fiscalización, si la denunciante es la Inspección del Trabajo; o los documentos que den cuenta de actuaciones administrativas junto con los antecedentes suficientes en que se funde la supuesta vulneración, o solo los últimos, según si el trabajador ha sido o no separado, respectivamente ${ }^{8}$;

- En el Procedimiento monitorio (PM): Deben acompañarse los antecedentes llevados a la Inspección del Trabajo y el acta que ella levante';

- En el Procedimiento de Reclamación de Multas y demás Resoluciones Administrativas (PRMA): Depende si se le aplican las reglas del PAG o del PM, según la cuantía de lo discutido ${ }^{10}$.

c. En la audiencia misma de juicio o de contestación, conciliación y prueba:

Ocasión por excelencia para incorporar todos los medios probatorios ${ }^{11}$.

d. En una nueva audiencia especial del PAG o PTL:

Audiencia que se abre para el solo efecto de presentar el oficio o informe pertinente que no llegó a la audiencia de juicio, o para que declare el absolvente que no asistió a la misma por motivo grave y justificado ${ }^{12}$.

e. Ante las Cortes de Apelaciones:

Siguiendo las reglas generales cuando conoce de un recurso de apelación, mientras no sea contrario a los princi-

\footnotetext{
${ }^{8}$ Artículos 486 inciso $5^{\circ}, 490$, y 489 en relación al 446 inciso $2^{\circ}$ del C. del Trabajo.

${ }^{9}$ Artículo 499 incisos $2^{\circ}$ y $3^{\circ}$ del C. del Trabajo.

${ }^{10}$ Artículos 503 inciso $4^{\circ}$, y 504 del C. del Trabajo.

${ }^{11}$ Artículo 454 del C. del Trabajo para los PAG y PTL, y artículo 500 inciso $5^{\circ}$ para el PM. Dentro de las mismas, el artículo $454 \mathrm{~N}^{\circ} 1$ inciso $3^{\circ}$ permite expresamente que, por causa justificada, se anticipe o postergue la rendición de los medios de prueba, pero esta alteración al orden no constituye, en la forma que se plantea en este trabajo, una etapa diversa para rendir la prueba. En todo caso, es útil para abogados que tuvieren que asistir a dos o más audiencias en un mismo día.

${ }^{12}$ Artículo 454 Nos 7 y 10 del C. del Trabajo.
} 
pios formativos del proceso laboral ${ }^{13}$, y cuando se intenten probar ciertos vicios que funden el recurso de nulidad ${ }^{14}$.

\section{2 Oportunidades NO REguladas eXPlí- citamente por el C. Del Trabajo}

La delimitación de los procedimientos a dos audiencias en el PAG o PTL o a una en el $\mathrm{PM}^{15}$, unido al principio de inmediación ${ }^{16}$ y celeridad, dificultan expresamente la apertura de otras instancias probatorias que impliquen extender la toma de conocimiento del juez. No obstante ello, por motivos graves y justificados, conviene revisar qué otras o nuevas instancias de prueba podrían concederse, tomando en cuenta las mismas escasas reglas del C. del Trabajo, las normas que regulan procedimientos análogos de acuerdo a una interpretación sistemática de nuestro ordenamiento jurídico (artículo 22 del C. Civil) ${ }^{17}$, y el respeto a los derechos fundamentales de una legítima defensa y un debido proceso ${ }^{18}$ (artículo $19 \mathrm{~N}^{\circ} 3$ de la Constitución Política).

\section{a. Prueba anticipada:}

Es aquella que requiere ser rendida con antelación al tiempo procesal fijado por la ley, sea antes del juicio (medida prejudicial probatoria) o durante él (luego de notificada la demanda).

${ }^{13}$ Artículo 476 en relación a los artículos 432 y 474 del C. del Trabajo, que a su vez remiten a los artículos 207, 227 y 159 del C. de Procedimiento Civil.

${ }^{14}$ Artículos 429 y 481 inciso $3^{\circ}$ del C. del Trabajo.

15 Véase artículos 450 y 500 inciso $5^{\circ}$ del C. del Trabajo.

${ }^{16}$ Véase artículos 425, 427 y 460 del C. del Trabajo.

17 Debe considerarse que tanto el artículo 418 del

C. del Trabajo como el 118 de la Ley $N^{\circ} 19.968$ (que crea los Tribunales de Familia), se remiten a los juzgados de garantía y tribunales de juicio oral en lo penal en lo que a organización jurisdiccional y administrativa se refiere. Frente a estructuras parecidas, podría esperarse también lógicas de funcionamiento similar, ya que de una determinada forma de ser se espera una determinada forma de obrar (véase Sото Kloss (1996) pp. 20-22.

18 Véase Taruffo (2008) pp. 56 a 58 ( $\$ 37$ a 39).
Dejando las medidas prejudiciales probatorias para después, debe primero reconocerse que no podría intentarse una rendición de prueba testimonial o confesional antes de la audiencia preparatoria dentro de un PAG o PTL, o antes de la única audiencia dentro de un PM, ya que el legislador no estableció la hipótesis de otras audiencias por lo que podría llegar a ser contrario a la ley la celebración de audiencias no contempladas. Sin embargo, ello no impediría rendirlas en la misma audiencia preparatoria del PAG o PTL, siempre que las dirija y falle el mismo juez de la audiencia de juicio, en razón del principio de inmediación y de la limitación en el número de audiencias conforme a los artículos 427, 450 y 460 del C. del Trabajo. En relación a otras pruebas y sin la necesidad de tener que celebrar audiencias para su aporte o incorporación, no debiera limitarse el aporte anticipado como documentos, certificados de ministro de fe, objetos, informes periciales, inspecciones personales del juez, etc., siempre que hubiese causa grave y justificada que prudentemente recomiende no esperar hasta la audiencia de juicio ${ }^{19}$. Dentro de un PM podría ser más forzosa la petición de una prueba anticipada ante la víspera de una única audiencia, que podría ser solicitada repentinamente por alguna de las partes vencidas si el fallo fue dictado con el solo mérito de la demanda ${ }^{20}$, más para el actor si quiere precaver una eventual demanda reconvencional, que se interpone y da traslado en la misma única audiencia. Para luchar contra una posible indefensión probatoria, en este último escenario, el actor vencido debería ofrecer o pedir pruebas, en la reclamación, para rendirlas en la audiencia única (v. gr. un peritaje, un infor-

${ }^{19}$ A modo de ejemplo, el temor fundado de que los documentos u objetos se perderán o extraviarán; que un testigo clave o eventual absolvente podría desaparecer o salir del lugar del juicio; o que el estado de un lugar implicado podría modificarse si se deja esperar la inspección personal del juez.

${ }^{20}$ Véase el artículo 500 inciso $5^{\circ}$ del C. del Trabajo, que ordena que la audiencia de contestación, conciliación y prueba debe celebrarse dentro de los 15 días desde la interposición del reclamo, pero no indica un mínimo de días entre que se notifica la resolución del reclamo y se fija la audiencia, pudiendo ser de un día para otro. 
me pericial, etc.), ya que de lo contrario, el juez no podría citar a otra audiencia para rendirlas ya que debe fallar al término de aquella (artículo 501 inciso $3^{\circ}$ del C. Laboral).

Hay normas del mismo que podrían sustentar una prueba anticipada, con la prevención de que las declaraciones de testigos o de partes solo podrían realizarse fuera de la audiencia de juicio, en la audiencia preparatoria. Así, el artículo 429 inciso $1^{\circ}$ del C. del Trabajo permite al juez decretar pruebas cuando lo estime necesario. Por otra parte, esta situación tiene una naturaleza incidental que también admitiría prueba, en casos graves, según se explica más adelante. Finalmente, apoya esta tesis el artículo 444 inciso $5^{\circ}$ que faculta al juez para requerir información a ciertas entidades luego de notificada la demanda, con el objeto de mantener una medida cautelar.

En los otros procedimientos de audiencia se permite la prueba anticipada. En el proceso penal este asunto está expresamente regulado en los artículos 191, 191 bis, 192 y 280 del código del ramo. De igual forma en el artículo $61 \mathrm{~N}^{\text {os }} 9$ y 10 de la Ley $\mathrm{N}^{\circ} 19.968$ para los casos de familia.

b. Prueba como medida prejudicial probatoria ${ }^{21}$ :

Ya algo se dijo en la letra anterior, basándose en las mismas hipótesis fácticas de urgencia o gravedad.

Legalmente, podría también autorizarse sobre los artículos 429 inciso $1^{\circ}$ y 432 , en relación a los artículos 281, 283, 284 y 286 del C. de Procedimiento Civil (referidos a ciertas medidas probatorias). Súmese el que su naturaleza también sería incidental, por lo que cabría aplicar supletoriamente las normas que más adelante se indican. Por último y más directamente, los incisos $3^{\circ}$ y $4^{\circ}$ del artículo 444 del C. del Trabajo autorizarían las medidas prejudiciales probatorias.

En forma paralela, el nuevo proceso penal regula esta materia en sus artículos 171 , 180 incisos $2^{\circ}$ y $3^{\circ}, 181,187,188,190,198$, 199 , entre otras, aunque no dice que puedan utilizarse las medidas probatorias del C. de Pro-

\footnotetext{
21 Sobre la existencia de medidas cautelares probatorias, véase CASARINo (2005) p. 203.
}

cedimiento Civil (artículo 157 del C. Procesal Penal). En el procedimiento de familia se permiten también esta clase de medidas en virtud del artículo 22 incisos $2^{\circ}$ y $3^{\circ}$, y otras reglas especiales (artículos 71, 83, 85, 88, 89 y 91).

\section{c. Prueba de incidentes:}

Los incidentes están expresamente reconocidos en el artículo 443 del C. del Trabajo, pero no la prueba que posiblemente amerite rendirse respecto de ellos. Sin embargo, sería útil su regulación ya que serviría para tramitar controversias accidentales que requieran de prueba, como: posibles excepciones dilatorias, pruebas anticipadas, medidas cautelares, pruebas sobre prueba o pruebas nuevas, entre otras.

Ahora bien, acá se plantea la posibilidad de rendir prueba fuera de las audiencias, por motivos graves y justificados, y sin ánimo dilatorio. Concretamente, en virtud nuevamente del artículo 429 inciso $1^{\circ}$ y del 432 del C. Laboral, que remite a los artículos 85 y 89 del C. de Enjuiciamiento Civil, podría permitirse la prueba de incidentes aunque si se trata de declaraciones o absoluciones, estas no podrían rendirse más que en las respectivas audiencias de cada procedimiento y siempre que las dirija y falle el mismo juez, por efecto del principio de inmediación y de los artículos 427, 450, 460 y 501 inciso $3^{\circ}$ del C. del Trabajo.

Los incidentes son igualmente reconocidos en el nuevo proceso penal, pero no se observa una norma general que autorice a rendir pruebas sobre ellos (artículo 290 del C. Procesal Penal), sin perjuicio de los artículos 63 y 271 del mismo código para situaciones específicas. En el procedimiento de familia expresamente se autoriza a rendir prueba por incidentes promovidos fuera y dentro de las audiencias (artículo 26 de la Ley $\left.\mathrm{N}^{\circ} 19.968\right)$.

Eventualmente, para casos muy calificados en que se configure un caso fortuito o fuerza mayor, relativo a la prueba ${ }^{22}$, podría necesitarse suspender el procedimiento laboral o incluso la audiencia misma, lo que debe constar por algún

22 V. gr. la pérdida o extravío de documentos u objetos, la ausencia justificada de un testigo, o que se entorpezca la inspección personal del juez o la rendición de otro medio probatorio. 
medio, hecho que en principio estaría permitido hacerlo de forma general por el C. Laboral en su artículo 426 inciso $3^{\circ}$ y de forma especial en sus artículos $453 \mathrm{~N}^{\circ} 1$ inciso $4^{\circ}$, y $454 \mathrm{~N}^{\text {os }} 7$ y 10. Similarmente, el C. Procesal Penal recoge el caso fortuito o fuerza mayor u otro obstáculo grave, y faculta al interviniente recurrir o pedir un nuevo plazo para realizar la actuación procesal afectada (artículos 17, 22 inciso $2^{\circ}, 33$ inciso $2^{\circ}, 82$ inciso $1^{\circ}, 283$ inciso $1^{\circ}$, y 300 letra d)). De igual modo la Ley $\mathrm{N}^{\circ} 19.968$ en sus artículos 15 inciso $3^{\circ}$, y 35 letra d).

\section{d. Prueba nueva:}

Podría ocurrir que justificadamente no se haya sabido de ciertos hechos o medios de prueba, o que se ventilaren nuevos antecedentes luego en la audiencia como consecuencia, por ejemplo, de una demanda reconvencional o excepción dilatoria que se presentan en la audiencia única del PM. Se relaciona este tema también con las medidas para mejor resolver.

Siempre en el contexto de casos graves y justificados, la prueba nueva podría permitirse en razón de los artículos 429 inciso $1^{\circ}$ (facultad del juez para pedir pruebas) y $454 \mathrm{~N}^{\circ} 9$ inciso $2^{\circ}$ (facultad del juez para pedir aclaraciones) del C. del Trabajo, sin perjuicio de las normas vistas para los incidentes y casos de suspensión ${ }^{23}$. Converge además el artículo 432 del mismo texto que remite a los artículos 321,322 y 326 inciso $2^{\circ}$ del C. de Procedimiento Civil sobre prueba nueva y al 159 de igual código sobre medidas para mejor resolver, en única o primera instancia; y nuevamente los mismos preceptos 432 y 474 del C. Laboral en relación al artículo 207 del C. de Procedimiento Civil sobre prueba nueva y al 159 del mismo sobre medidas para mejor resolver, cuando hay apelación.

23 Ante un caso extremo, podría necesitarse suspender la audiencia de juicio del PAG o PTL o la única del PM, y citarse a una nueva donde se rindan tanto los medios ofrecidos como los nuevos ad hoc, con miras a no parcelar - por principio de concentración- la audiencia en la que se deben rendir y así permitir la dictación de la sentencia al final de la misma sobre la observación conjunta de todos los medios pertinentes y relevantes (artículos 457 y 501 inciso final del C. Laboral).
Del mismo modo, el C. Procesal Penal da lugar a la prueba nueva dentro de cierto margen (artículos 336 inciso $1^{\circ}$ y 278), pero derechamente no admite las medidas para mejor resolver; mientras que la Ley $\mathrm{N}^{\circ} 19.968$ admite la prueba nueva bajo ciertos requisitos (artículo 63 bis inciso $1^{\circ}$ ) y, aunque algo dudoso, se podría reconocer un tipo de medida para mejor resolver en su artículo 64 inciso $6^{\circ}$.

\section{e. Prueba sobre prueba:}

Utilizada en el caso de tener que acreditar la licitud, conexión, pertinencia, importancia, veracidad ${ }^{24}$, autenticidad, integridad, etc. de algún medio probatorio.

Aunque no latamente, el artículo $454 \mathrm{~N}^{\circ}$ $2^{\circ}$ abre la puerta a una revisión de la prueba documental cuando se discute su licitud, por lo que la prueba sobre prueba no sería una institución tan ajena a estos procedimientos. Sin embargo, no hay referencia a otros medios, en cuyo caso y tratándose de casos graves y justificados, podría igual concederse en atención al aforismo que reza que a la misma razón, la misma disposición, tomando como expresión de esa razón el citado artículo $454 \mathrm{~N}^{\circ} 2$ del C. del Trabajo. Ello sin perjuicio de los artículos 429 inciso $1^{\circ}$ y $432 \mathrm{del}$ mismo cuerpo legal, que remiten a los artículos 344, 346 y 350 a 355 del C. de Enjuiciamiento Civil, y de las normas sobre incidentes, casos de suspensión ${ }^{25}$ y prueba nueva antes expuestas.

${ }^{24} \mathrm{Al}$ respecto, léase el artículo 509.: "Las personas que incurran en falsedad en el otorgamiento de certificados, permisos o estado de salud, en falsificación de estos, o en uso malicioso de ellos, serán sancionadas con las penas previstas en el artículo 202 del Código Penal." ${ }^{25} \mathrm{~A}$ modo de ejemplo y dentro del C. del Trabajo, se puede generar un incidente con ocasión de un perjurio (artículo $454 \mathrm{~N}^{\circ} 5$ inciso $4^{\circ}$ ) o para la alegar la falsedad de ciertos documentos (artículos $454 \mathrm{~N}^{\circ} 2$ y 509), hechos que requerirían ser probados, lo que a su vez podría ameritar suspender el llamado para lograr una rendición completa de todas las pruebas en una única audiencia, por principio de concentración y de inmediación. Además, supletoriamente podría pedirse suspensión en base a los artículos 426 inciso $3^{\circ}$ y 432 que remiten al 167 del C. de Enjuiciamiento Civil. esto, sin perjuicio del recurso de revisión que podría intentar la parte agraviada, de acuerdo el artículo 810 del C. de Procedimiento Civil. 
Nuevamente el C. Procesal Penal toma la prueba sobre prueba y la trata expresamente (artículo 336 inciso $2^{\circ}$ ), al igual que lo hace el procedimiento de familia (artículo 63 bis inciso $2^{\circ}$ de la Ley $\left.\mathrm{N}^{\circ} 19.968\right)$.

\section{CONCLUSIÓN Y ALGUNAS CONSIDERACIONES FINALES}

Los nuevos procedimientos laborales no ofrecen explícitamente mayores oportunidades de prueba. Esto deriva quizá de la intención del legislador de querer limitar al máximo la dilación del juicio pensando en la mayor protección del trabajador. Sin embargo, y por muy bien intencionada que haya sido dicha autoridad, llama la atención que haya reducido tanto esas instancias, en contraste con los otros procedimientos de audiencia (penal nuevo y de familia).

Cabe recordar que aquellos otros sistemas también buscan salvaguardar intereses elevados, paralelos a la justicia, en contextos de inmediación y concentración, tales como la integridad y libertad del imputado -lo que inspira el principio pro reo-, y los derechos y necesidades del niño, y muchas veces también los de la mujer -lo que inspira interpretaciones pro menor y pro mujer, respectivamente-; pero divergen enormemente de los nuevos procedimientos laborales al dar aquellos regulación expresa a más instancias probatorias.

Empero, sobre una interpretación pro operario de las normas del trabajo, acompañado otras tantas veces de jueces pro operario, parece difícil que puedan concederse esas otras oportunidades para pruebas relevantes o que sirven para acreditar hechos de contexto, máxime cuando el que las solicita es la parte empleadora o cuando lo que se busca es acreditar la realidad de un proceso productivo o entrega de un servicio. Nótese que por lo general el demandante será el trabajador y su abogado de seguro desarrollará su estrategia judicial sobre la base de las instancias probatorias existentes, pero no necesariamente el demandado, quien contra el tiempo deberá recurrir a todo lo que esté a su alcance para probar sus dichos ya que no existen presunciones que lo favorezcan.

Así, y considerando los principios y normas laborales, se intentó, pretensiosamente, aunque de forma fundada, nutrir de algunas herramientas jurídicas que habiliten al litigante, en casos justificados y graves, luchar por una oportunidad probatoria de excepción con la que pueda dar razón de sus diversas alegaciones, a la vez que permita elevar los niveles de conocimiento del juez sin riesgo mayor de ralentizar el procedimiento, como no se aprecia que ocurra ni en los sistemas penales reformados ni en los de familia.

\section{BIBLIOGRAFÍA}

Casarino Viterbo, Mario (2005): Manual de Derecho Procesal (Santiago, Editorial Jurídica de Chile).

Sото Kloss, Eduardo (1996): Derecho Administrativo, vol. II (Santiago, Editorial Jurídica de Chile).

Taruffo, Michele (2008): La prueba (Traducc. Laura Manríquez y Jordi Ferrer Beltrán, Barcelona, Editorial Marcial Pons).

\section{NORMAS}

Código de Procedimiento Civil

Código del Trabajo

Código Procesal Penal

Constitución Política de la República de Chile

Ley 19.968, Crea los Tribunales de Familia. Diario Oficial, 30 de agosto de 2004. 